\title{
Crenças que influenciam adolescentes na doação de órgãos*
}

\author{
BELIEFS THAT INFLUENCE ADOLESCENTS IN ORGAN DONATIONS
}

\section{CREENCIAS QUE INFLUYEN EN LOS ADOLESCENTES PARA LA DONACIÓN DE ÓRGANOS}

\author{
Márcia Wanderley de Moraes', Maria Cecília Bueno Jayme Gallani², Paolo Meneghin ${ }^{3}$
}

*Extraído da dissertação
"Caracterização dos
determinantes sócio-
culturais que influenciam
adolescentes na atitude
de ser doador de órgãos",
Escola de Enfermagem
da USP, 2001.
1 Enfermeira. Mestre em
Enfermagem pela
EEUSP. Docente da
Faculdade de
Enfermagem do Hospital
Israelita Albert Einstein.
2 Professora Doutora do
Departamento de
Enfermagem da
Faculdade de Ciências
Médicas da UNICAMP
3 Professor Doutor do
Departamento de
Enfermagem Médico-
Cirúrgica da EEUSP.
Orientador.
paolomen@usp.br

\section{RESUMO}

Foram objetivos do estudo identificar conhecimento, crenças comportamentais e normativas de estudantes de nível médio sobre transplante e doação de órgãos, à luz da Teoria da Ação Racional (TRA), em duas escolas da rede pública do município de São Paulo. A amostra foi constituída por 94 alunos que responderam um questionário baseado nos pressupostos da TRA e as respostas foram submetidas à análise estatística. $\mathrm{O}$ resultado mostra baixo conhecimento sobre doação de órgãos, pois $45,8 \%$ desconhecem o conceito de morte encefálica; 37,2\% não sabem quando a morte ocorre e $70,3 \%$ não sabem quando uma pessoa se torna potencial doador. Foram evidenciadas dez crenças positivas relativas ao comportamento de ser doador de órgãos. Salientaram-se, também, sete crenças negativas sobre doação de órgãos. Foram evidenciadas oito crenças positivas e cinco crenças negativas relativas à doação de órgãos. Conclui-se ser necessário desenvolver estudos e implementar programas educativos de esclarecimento sobre o tema.

\section{ABSTRACT}

This study was aimed at investigating knowledge, behavior and normative beliefs of students concerning transplant and organs donations, based on the Theory of Reasoned Action (TRA), in two public schools of the city of São Paulo. The sample was comprised of 94 students who answered a questionnaire, whose answers were submitted to statistical analysis. The results showed that the group had little knowledge about organ donation because $45.8 \%$ were not familiar with the concept of encephalic death, $37.2 \%$ do not know when death occurs and $70.3 \%$ do not know when a person becomes a potential organ donor. Eight positive and five negative beliefs about organ donations were detected. The conclusion is that it is necessary to develop studies and to implement education programs to clarify the population about this topic.

\section{KEY WORDS}

Educação em saúde.

Comportamento do adolescente.

Transplantes.
Health education.

Adolescent behavior.

Transplants.

\section{RESUMEN}

Los objetivos del estudio fueron identificar el conocimiento, creencias de comportamiento y normativas de estudiantes de nivel medio respecto al transplante y donación de órganos, a la luz de la Teoría de la Acción Racional (TRA), en dos escuelas de la red pública del municipio de Sao Paulo. La muestra estuvo constituida por 94 alumnos que respondieron un cuestionario basado en las premisas de la TRA y las respuestas fueron sometidas al análisis estadístico. El resultado muestra bajo conocimiento sobre donación de órganos, pues el 45,8\% desconoce el concepto de muerte encefálica; el $37,2 \%$ no sabe cuándo ocurre la muerte y el 70,3\% no sabe cuándo una persona se torna en potencial donador. Fueron evidenciadas diez creencias positivas relativas al comportamiento de ser donador de órganos. Resaltaron, también, siete creencias negativas sobre donación de órganos. Se evidenciaron ocho creencias positivas y cinco creencias negativas relativas a la donación de órganos. Se concluye que es necesario desarrollar estudios e implementar programas educativos para aclarar a las personas sobre el tema.

\section{DESCRIPTORES}

Educación en salud.

Conducta del adolescente. Transplantes. 


\section{INTRODUÇÃO}

Os transplantes de órgãos vêm assumindo importante papel no tratamento de doenças terminais sem possibilidade de terapêutica clínica ou cirúrgica e os resultados obtidos estão contribuindo para uma sobrevida mais digna dos pacientes que necessitam desta intervenção. Em alguns tipos de transplantes, como o cardíaco e o renal, o domínio das técnicas cirúrgicas e o advento de medicamentos específicos bem como a mudança de hábitos, favorecem uma sensível melhora na qualidade de vida dos pacientes submetidos a esses procedimentos.

Segundo a Organização Mundial de Saúde (OMS), o termo órgão humano inclui órgãos e tecidos, mas que não se estendem a tecidos reprodutivos como óvulos, esperma, ovário, testículos, embriões, nem ao sangue ou a seus constituintes. Atualmente, são realizados transplantes de múltiplos órgãos e tecidos como coração, fígado, pulmão, pâncreas, rins, córneas, pele, ossos, veias, tendões e medula óssea, regulamentados no mundo todo pela $\mathrm{OMS}^{(1)}$.

O transplante de órgãos humanos e a doação de órgãos são temas polêmicos que têm despertado interesse e discussões em várias comunidades. A falta de esclarecimento, o noticiário sensacionalista sobre tráfico de órgãos, a ausência de programas permanentes voltados para a conscientização da população e o incentivo à captação de órgãos, contribuem para alimentar dúvidas e arraigar mitos e preconceitos ${ }^{(2)}$.

Talvez, por essas razões, haja número insuficiente de doadores e grande perda de potenciais doadores, prolongando o sofrimento de pacientes que dependem da doação de órgãos, condenando-os a permanecer numa interminável fila de espera.

Muitas pessoas verbalizam a intenção de se tornar doadores de órgãos, porém o desconhecimento das resoluções existentes, da legislação e demais aspectos que envolvem este tema, prevalece por ocasião da tomada de decisão, prioritariamente no que concerne ao conceito de morte, e, em especial, ao de morte encefálica.

Determinar o conceito e o momento exato da morte, estabelecer critérios e diagnósticos, assim como a aplicação destes sob as óticas médica, legal e ética, tem sido tema polêmico. A nomenclatura do termo morte, por sua vez, também sofreu variações como morte cerebral, morte do sistema nervoso, coma depassé, Glasgow 3, para, finalmente, chegar ao termo morte encefálica ${ }^{(2)}$.
A partir da década de 1950, muitos protocolos foram estabelecidos para definir a morte encefálica. Estas regras são variáveis de um país para outro e até mesmo entre grandes metrópoles. O diagnóstico de morte encefálica está subordinado a determinados protocolos que, de forma genérica, se constituem da anamnese e exame físico completos, sendo ainda confirmados por outros testes e diagnósticos ${ }^{(3)}$.

No Brasil, aceitou-se oficialmente o termo morte encefálica a partir da Resolução 1346/91, atualizada através da Resolução 1480/97 do Conselho Federal de Medicina, que propõe uma mescla de protocolos, destacando-se como critérios clínicos o coma profundo arreativo e aperceptivo, apnéia, midríase paralítica bilateral e o reflexo óculo-motor ausente $^{(4-5)}$. Tais parâmetros devem ser mantidos inalterados por período superior a seis horas, além de haver a obrigatoriedade da realização de testes de confirmação. Só então poder-se-á considerar o indivíduo como um potencial doador de órgãos e tecidos ${ }^{(6)}$.

A doação de órgãos, no Brasil, é uma concessão graciosa feita em vida, pelo próprio doador ou, após sua morte, por seu representante legal. Pode ser realizada através de expressão verbal com testemunhas ou de documento oficial, escrito, no qual declara, estando em pleno gozo de suas faculdades mentais, ser de sua vontade doar órgãos ou tecidos de seu corpo, após sua morte, por meio de testamento ou em vida, por declaração $0^{(7)}$.

Muitas pessoas enfrentam um dilema quando se deparam com a necessidade de optar ou não por ser doador de órgãos, como ocorre nas emissões de documentos. Essas situações, muitas vezes, geram conflitos de crenças, de valores e de princípios religiosos, além de esbarrar com desinformação, mitos e crendices populares sobre o assunto.

Por ocasião do desenvolvimento de atividades educativas junto a adolescentes em escolas de nível médio, percebemos, por meio das perguntas feitas pelos estudantes, que muitos dos fatores que levavam ao preconceito, estavam presentes nas dúvidas verbalizadas por eles, fruto talvez da estrutura educacional e religiosa na qual foram formados ou simplesmente pela ignorância do tema.

Da mesma forma, quando da abordagem feita a familiares de potenciais doadores, realizada por nós e por outros colegas, alguns desses fatores estavam presentes e se constituíam em elementos responsáveis pela maioria das recusas de familiares em doar órgãos do parente morto. 
Podemos dizer que a observação de tais características foi o motivo que nos compeliu a elaborar este estudo para comprovar, por meio do método científico, que fatores, entre uma população de adolescentes, são mais determinantes na recusa ou na aceitação de se tornar um doador ou de doar órgãos de familiares mortos.

\section{REFERENCIAL TEÓRICO}

Todas as teorias comportamentais são unânimes quando afirmam que se deve descobrir o que as pessoas sabem sobre determinado tema, analisar este conhecimento à luz das crenças e valores de um grupo específico a fim de se perceber as intenções dessas pessoas e prever comportamentos em relação ao problema em questão ${ }^{(8)}$.

Uma dessas teorias é a Theory of Reasoned Action $T R A$ - Teoria da Ação Racional ${ }^{(9)}$. Oriunda da área da Psicologia Social, a TRA se fundamenta no pressuposto básico que o ser humano, sendo uma espécie racional, faz uso de modo sistemático, implícito ou explícito, das informações disponíveis, sejam elas completas ou não, verídicas ou não, para então formar o que se convencionou chamar de intenção de comportamento ${ }^{(10)}$.

Esta teoria tem como objetivos predizer e compreender o comportamento do indivíduo, sendo necessário percorrer duas etapas para atingi-los. A primeira etapa consiste na identificação e mensuração do comportamento de interesse de um determinado grupo sobre um dado assunto. Uma vez que, de acordo com os pressupostos da TRA, a maioria das ações de relevância social está sob controle voluntário, os autores atestam que a intenção de uma pessoa em realizar, ou não, certo comportamento é determinante imediato da ação. Embora não exista uma perfeita correlação entre o dizer e o fazer, na maioria dos casos, as pessoas se comportam de acordo com sua intenção ${ }^{(9-10)}$.

A segunda etapa procura entender a formação da intenção, ou seja, identificar seus determinantes por meio da aplicação de modelos matemáticos que permitam evidenciar os fatores com maior peso relativo na construção da intenção de comportamento. De acordo com a TRA, a intenção do indivíduo é função de dois determinantes básicos: um de natureza pessoal e outro que reflete a influência social. $\mathrm{O}$ fator pessoal é a avaliação positiva ou negativa do indivíduo quanto a realizar o comportamento e é denominado atitude, formada essencialmente pelas crenças comportamentais. O segundo fator determinante da intenção é a percepção que o indivíduo tem das pressões sociais exercidas sobre ele para realizar ou não o comportamento em questão, e recebe a denominação de norma subjetiva que, por sua vez, é formada pelas crenças normativas $^{(9-10)}$.

Assim, a intenção do indivíduo em realizar o comportamento vai depender do julgamento que ele faz acerca da realização desse comportamento (crenças comportamentais) e da impressão que ele tem dos referentes que lhe são importantes, de aprovarem ou não a realização do comportamento (crenças normativas).

A relação entre comportamento, intenção, atitude e normas subjetivas pode ser representada de acordo com o seguinte diagrama:

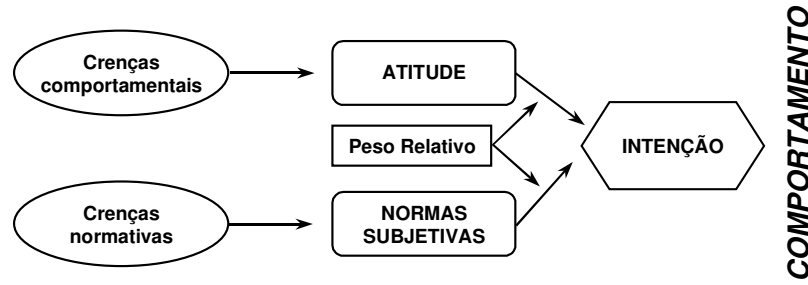

Figura 1 - Diagrama representativo das relações entre os fatores que determinam o comportamento do indivíduo, de acordo com a TRA ${ }^{(9-10)}$.

A utilização da TRA por enfermeiros que pretendem planejar programas de educação em saúde, visando a mudanças de comportamento, se assenta na possibilidade de construir uma estrutura de intervenção direcionada especificamente para as causas ou fatores determinantes de um dado comportamento $^{(10)}$.

Além disso, programas educativos baseados em referenciais teóricos adequados, imprimem ao trabalho do enfermeiro o rigor científico necessário para quem pretende desenvolver suas atividades na esfera do planejamento da educação em saúde.

Antes de o referencial teórico ser aplicado para determinar o poder de predição do comportamento, a partir dos constructos de atitudes e normas subjetivas, é necessário o reconhecimento das crenças salientes em relação ao comportamento investigado no grupo em estudo. Crenças salientes são as crenças mais comuns, originadas do universo de pensamentos de um determinado grupo, sobre um dado assunto.

Neste sentido, a doação de órgãos e o transplante são temas complexos, sobre os quais é sabido existir concepções equivocadas por grande parcela da população e que, por sua vez, poderiam influenciar as crenças relativas à doação de órgãos.

Sendo assim, este estudo realizado junto a adolescentes teve como objetivos:

- avaliar o conhecimento sobre transplante e doação de órgãos;

- identificar as crenças salientes, pessoais e normativas, em relação ao transplante e doação de órgãos. 


\section{CASUÍSTICA E MÉTODO}

Tratou-se de um estudo do tipo descritivo, no qual os dados foram colhidos em duas escolas da rede pública do município de São Paulo, com alunos do ensino médio, do período diurno e noturno durante o primeiro semestre letivo de 2002.

A amostra foi constituída por 94 alunos, sendo 64 do sexo feminino e 30 do sexo masculino, com idade entre $16 \mathrm{e}$ 18 anos, regularmente matriculados no ensino médio, em escolas que autorizaram o estudo e após o projeto ser aprovado por Comitê de Ética em Pesquisa. Os critérios de inclusão foram: ter interesse em participar, respondendo ao questionário; quando menor de 18 anos, devolver o Termo de Consentimento Livre e Esclarecido (TCLE) assinado pelos pais ou responsáveis; quando maior de 18 anos, devolver TCLE assinado pelo próprio estudante.

A realização da primeira etapa dos estudos desenvolvidos com a TRA, geralmente é feita por meio de entrevistas semi-estruturadas, onde o entrevistado é estimulado a responder o que sabe, pensa e acredita sobre determinado assunto ou situação. Neste trabalho, porém, optou-se pela entrevista estruturada, com o uso de questões fechadas, tendo em vista que o grupo estudado era constituído por adolescentes que compareciam à escola apenas para assistir às aulas, tornando-se difícil marcar entrevistas individuais antes ou após o horário letivo.

A construção do instrumento para a colheita de dados, então, baseou-se nos pressupostos da TRA e em modelos validados em estudos científicos ${ }^{(9-12)}$

O instrumento para coleta de dados compõe-se das seguintes partes:

I - perfil sócio-demográfico, para se obter dados como: sexo, idade, cor, procedência, religião, estado civil, ocupação, condição de co-habitação, tipo de estabelecimento que cursou o primeiro grau, escolaridade dos pais, que meios disponíveis na mídia foram utilizados para obter informações e atividades que exerce. Foi investigada, também a intenção em realizar o comportamento: variável categórica SIM (seria doador de órgãos), NÃO (não seria doador de órgãos) e a situação atual: SIM (é doador de órgãos), NÃO (não é doador de órgãos);

II - conhecimento específico sobre a doação de órgãos e transplante: mensurado através de sete questões de múltipla escolha, com apenas uma resposta certa para cada questão. Para a análise estatística foi elaborado um escore de conhecimento, sendo $\geq 04$ (superior a 50\%) ou $<04$ (inferior a $50 \%$ );

III - mensuração das crenças comportamentais salientes: realizada por meio de três questões, sendo a primeira com nove, a segunda com quatro e a terceira também com quatro afirmativas, numa escala, tipo Likert, de 5 pontos; mensuração das crenças normativas feita por meio de duas questões e, finalmente, mensuração da motivação para aderir ao comportamento, realizada por meio de uma questão com seis itens, numa escala tipo Likert de 3 pontos.

\section{ANÁLISE DOS DADOS}

Todos os dados colhidos, depois de codificados, foram inicialmente transportados para uma planilha de dados do programa Excel for Windows e, então, ao programa $S A S$ System for Windows, versão 8.1 para a realização das seguintes análises: descritiva; medida de comparação de proporções (variáveis categóricas): qui-quadrado ou teste Exato de Fischer. O nível de significância para os testes foi de 5\%; teste de consistência interna do instrumento. Mesmo não sendo este o instrumento definitivo para a realização da segunda etapa da TRA, foi aplicado o coeficiente $\alpha$ de Cronbach para verificar a consistência do instrumento.

\section{RESULTADOS E DISCUSSÃO}

Os participantes do estudo pertencem, em sua maioria, ao sexo feminino (68,1\% - 64/94), com idades entre 16 e 18 anos $(73,4 \%$ - 69/94), são brancos (63,8\% - 60/94), procedentes do município de São Paulo (93,6\% - 88/94).

A maioria dos participantes afirmou ser católica $(66,0 \%$ 62/94). Dentre as outras religiões citadas encontram-se 21,3\% de evangélicos, sendo os 10,6\% restantes pertencentes a outras religiões como espiritismo e budismo e os que afirmam não pertencer a nenhuma religião. Este perfil se coaduna com recentes dados estatísticos da população brasileira ${ }^{(13)}$.

Com relação ao estado civil, praticamente toda a amostra é solteira (97,9\% - 92/94); não trabalha (70,2\% - 66/94) e, ainda, reside com os pais ou parentes $(94,6 \%$ - 89/94), dado importante para este estudo pois pode-se inferir que a maioria das opiniões, crenças e valores expressos pelos estudantes possam retratar, também, o pensamento dos familiares.

Estudos relatam que a família exerce um papel fundamental na etapa de crescimento e desenvolvimento do adolescente propiciando o equilíbrio do indivíduo, já que ela é o primeiro vínculo de inter-relação com o seu meio social, além de nortear os valores e os princípios morais que os adolescentes vão seguir por toda a vida, ainda que possam reformular alguns preceitos familiares herdados ${ }^{(14-15)}$.

Quanto à escolaridade dos pais dos adolescentes desse grupo, os dados demonstram que 45,7\% (43/94) dos pais (genitor) e 46,8\% (44/94) das mães (genitora) têm o primeiro grau incompleto. 
De acordo com esses dados, pode-se induzir que, com a baixa escolaridade dos pais, os adolescentes participantes deste estudo não encontrem, no seio familiar, respostas ou argumentos para alimentar discussões sobre temas tão polêmicos a ponto de construir e fortalecer opiniões próprias que formarão a atitude face às diferentes situações na vida, como relatado na literatura, em outros problemas não menos conflitantes $^{(14)}$.

No que se refere aos meios de comunicação disponíveis na mídia, a forma como esses jovens referem tomar conhecimento e se atualizar sobre o tema transplante e doação de órgãos é atribuída à televisão (74,5\%), seguida pelo jornal $(25,5 \%)$ e por revistas $(14,9 \%)$.

A literatura é pródiga em referências demonstrando que os meios massivos de comunicação, apesar de sua grande penetração em âmbito nacional e mundial, não são os mais adequados para promover esclarecimento suficiente sobre temas polêmicos como é, entre outros, o da doação de órgãos. Ao contrário, muitas vezes a forma, a simbologia e o repertório utilizados pelos meios de comunicação de massa causam mais celeuma e confusão que esclarecimen$\operatorname{tos}^{(8,16-18)}$. Esta realidade se torna evidente quando se analisa o conhecimento dos estudantes sobre o tema.

O conhecimento dos participantes deste estudo sobre transplante e doação de órgãos pode ser considerado limitado principalmente sobre conceitos de morte encefálica e a respeito do potencial doador.

Pela análise das respostas, percebe-se que os estudantes confundem-se com o conceito de morte em caso de doação de órgãos. Nas questões onde se conceitua morte encefálica, quase a metade dos adolescentes (45,8\% - 43/ 94) não sabe ou tem conhecimento errôneo sobre o assunto.

Quanto ao momento em que ocorre a morte, 37,2\% (35/ 94) não sabiam ou manifestaram conceito errôneo, considerando como morte apenas a parada cardíaca, enquanto $23,4 \%$ (22/94) consideraram a perda da função cerebral como sendo a morte de fato, de acordo com a definição preconizada, hoje, na literatura.

Em relação ao potencial doador 70,3\% (66/94) não souberam definir quando uma pessoa pode ser considerada como tal e apenas $29,8 \%$ (28/94) responderam corretamente.

Assim, os meios de comunicação de massa, que poderiam ser um caminho para o esclarecimento de dúvidas, em muitos casos reproduzem informações distorcidas, superficiais e preconceituosas. A imprensa e os adolescentes perpetuam um círculo vicioso onde a mídia reproduz o que os jovens dizem e estes o que lhes foi passado pelos meios de comunicação $^{(19)}$.

Quando se apresenta aos estudantes uma situação hipotética como a de colocar o carimbo de doador ou não doador nos próprios documentos, 52,1\% (49/94) afirmaram que permitiriam o carimbo de doador.

Apesar de a maioria dos entrevistados afirmar que permitiria o carimbo de doador, o número de não doadores ainda é muito grande, principalmente se considerarmos que a mídia - principal fonte de informação dos participantes - vem demonstrando a necessidade de se aumentar o número de doadores e também tem retratado os problemas vividos pelas pessoas que precisam de transplante de órgãos.

No Brasil, a taxa de doadores é de 3,7 por milhão de habitantes por ano e apesar de um aumento expressivo do número de transplantes de $20 \%$ em 1998 e $30 \%$ em 1999 , apenas $30 \%$ dos órgãos de doadores em potencial são aproveitados. Em países desenvolvidos, calcula-se de 20 a 40 doadores por milhão de habitantes/ano, enquanto que nos países latino-americanos a média é de 10 a 12 doadores por grupo de milhão(20).

As equipes transplantadoras vêm enfrentando, como crescente desafio, a escassez de doadores de órgãos que têm, como uma das principais razões, a falta de notificação de potenciais doadores bem como a recusa familiar. Sabese, no entanto, que o número de doadores, embora tenha aumentado nos últimos anos, ainda não é suficiente para atender toda a demanda e muitos pacientes morrem, inscritos na fila única, à espera de um transplante ${ }^{(21)}$.

De acordo com levantamento da Associação Brasileira de Transplantes de Órgãos (ABTO), realizado anualmente em todos os estados brasileiros, a maior causa para não se efetivar uma doação ainda é a recusa familiar, seguida da contra-indicação médica. Este dado é confirmado quando se analisam 427 casos de notificações de potenciais doadores da Organização de Procura de Órgãos (OPO) da Santa Casa de Misericórdia de São Paulo onde a principal causa de insucesso da captação é a recusa familiar em 38,4\% dos casos e em $5,1 \%$, a recusa pessoal ${ }^{(22)}$.

Segundo a ABTO, o ano de 2000 registrou um número de 4,3 doadores cadáveres por milhão de habitantes por ano. Este é um valor ainda considerado baixo em relação aos índices internacionais, e alerta para que novas, constantes e mais efetivas medidas para implementar a doação de órgãos no país se fazem necessárias ${ }^{(22)}$.

Neste estudo, constatou-se que 74,5\% (70/94) dos estudantes afirmaram não ser doadores de órgãos, o que torna o quadro ainda mais dramático. Dados semelhantes foram obtidos em estudo realizado com clientes hospitalizados num hospital universitário de Recife (PE) onde apenas 37,5\% dos participantes declararam-se doadores ${ }^{(22)}$.

Algumas pesquisas realizadas entre estudantes universitários e profissionais liberais, porém, demonstram dados 
discordantes com os deste estudo. Pesquisa realizada com estudantes do curso de graduação em enfermagem, de uma instituição pública de São Paulo, demonstrou que $89,7 \%$ doariam os órgãos, 3,0\% não doariam e 7,2\% não opinaram. As justificativas citadas para a doação foram não precisar mais dos órgãos após a morte e ajudar outras pessoas. Os que não doariam seus órgãos citaram como justificativas: não permissão da religião, medo de falso diagnóstico de morte encefálica e receio do tráfico de órgãos, causas que também foram encontradas neste estudo ${ }^{(23)}$.
Estudo feito entre estudantes de medicina relatou que, dentre os participantes, $70,0 \%$ se declararam doadores; e uma pesquisa realizada com médicos professores de uma universidade particular do Estado de São Paulo, apontou que $87,0 \%$ doariam seus órgãos ${ }^{(24)}$.

Para verificar se a crença popular de que pessoas com maior nível de escolaridade têm intenção mais positiva quanto à doação de órgãos, foram relacionados os dados de escolaridade dos pais com a manifestação feita pelos adolescentes em serem, ou não, doadores de órgãos, como apresentado às Tabelas 1 e 2.

Tabela 1 - Freqüência e porcentagem de estudantes segundo a escolaridade do pai e intenção de doação de órgãos São Paulo - 2002*

\begin{tabular}{|c|c|c|c|c|c|c|}
\hline \multirow{2}{*}{$\begin{array}{l}\text { Intenção } \\
\text { Manifesta }\end{array}$} & \multicolumn{6}{|c|}{ Escolaridade do Pai } \\
\hline & $1^{\circ}$ grau & $\%$ & $2^{\circ}$ grau & $\%$ & superior & $\%$ \\
\hline SIM & 11 & 11,70 & 10 & 10,64 & 3 & 3,19 \\
\hline$\%$ total & & 45,83 & & 41,67 & & 12,50 \\
\hline NÃO & 49 & 52,13 & 14 & 14,89 & 7 & 7,45 \\
\hline$\%$ total & & 70,00 & & 20,00 & & 10,00 \\
\hline n total & 60 & & 24 & & 10 & \\
\hline
\end{tabular}

${ }^{*} \chi^{2}, \mathrm{p}$-valor $=0,08$

Tabela 2 - Teste Exato de Fisher entre a associação da escolaridade da mãe com a intenção manifestada pelos estudantes - São Paulo - 2002*

\begin{tabular}{|c|c|c|c|c|c|c|}
\hline \multirow{2}{*}{$\begin{array}{l}\text { Intenção } \\
\text { Manifesta }\end{array}$} & \multicolumn{6}{|c|}{ Escolaridade da Mãe } \\
\hline & $1^{\circ}$ grau & $\%$ & $2^{\circ}$ grau & $\%$ & superior & $\%$ \\
\hline SIM & 13 & 13,83 & 9 & 9,57 & 2 & 2,13 \\
\hline$\%$ total & & 54,17 & & 37,50 & & 8,33 \\
\hline NÃO & 43 & 45,74 & 24 & 25,53 & 3 & 3,19 \\
\hline$\%$ total & & 61,43 & & 34,29 & & 4,29 \\
\hline n total & 56 & & 33 & & 05 & \\
\hline
\end{tabular}

$*$ p-valor $=0,67$

Nesta amostra observou-se uma tendência dos adolescentes, filhos de pais com $1^{\circ}$ grau, de não serem doadores (qui-quadrado, p-valor= 0,08 ). $\mathrm{O}$ mesmo não foi observado em relação às mães, ou seja, não houve associação entre a intenção do adolescente em ser doador e o nível de escolaridade da mãe (Exato de Fisher, p-valor=0,67), apesar de algumas pesquisas indicarem uma relação mais positiva entre pessoas com maior nível de escolaridade e a intenção de doar órgãos ${ }^{(25)}$.
Em relação ao conhecimento dos adolescentes sobre doação de órgãos e transplante, primeiramente foi feita uma pergunta a respeito de sua opinião quanto ao próprio nível de conhecimento sobre o tema, se suficiente ou insuficiente, seguida por sete questões, de múltipla escolha, de conhecimento específico.

Neste grupo, apenas 19,1\% (18/94) consideraram ter conhecimento suficiente sobre o assunto. A análise das respostas mostrou que 64,8\% (61/94) acertaram menos de 4 questões (escore < 4) e 35,1\% (33/94) acertaram 4 ou mais questões (escore $\geq 4$ ), como se observa à Tabela 3 . 
Tabela 3 - Distribuição do escore de conhecimento específico e o conhecimento (suficiente / insuficiente) sobre transplante - São Paulo - 2002*

\begin{tabular}{|c|c|c|c|}
\hline \multirow{2}{*}{ Escore } & \multicolumn{3}{|c|}{ Conhecimento } \\
\hline & Suficiente & Insuficiente & Total \\
\hline \multicolumn{4}{|l|}{$<4$} \\
\hline Freqüência & 12 & 49 & 61 \\
\hline $\begin{array}{l}\text { Porcentagem } \\
\quad>4\end{array}$ & 12,77 & 52,13 & 64,89 \\
\hline Freqüência & 6 & 27 & 33 \\
\hline Porcentagem & 6,38 & 28,72 & 35,11 \\
\hline n Total & 18 & 76 & 94 \\
\hline$\%$ Total & 19,15 & 80,85 & 100,00 \\
\hline
\end{tabular}

$* \chi^{2}, \mathrm{p}$-valor $=0,86$

Aplicando o teste qui-quadrado entre as variáveis escore de conhecimento e o conhecimento sobre transplante, obteve-se um p-valor $=0,86$ concluindo-se que, tanto o grupo com escore maior quanto o com escore menor, apresentou deficiência de conhecimento. Esses dados, bem como os encontrados na literatura, falam a favor da necessidade de se implementar programas educativos para modificar tal situação ${ }^{(26-27)}$.

Para a categorização das crenças salientes foi adotado o critério de numerar todas as respostas, codificando-as em ordem crescente, sendo o escore 1 sempre atribuído às respostas negativas em relação ao comportamento esperado e o escore 5, às positivas, denominando-as de crenças mais favoráveis; e crenças menos favoráveis, para as negativas.

Foram identificadas oito crenças positivas em relação à doação de órgãos demonstrando intenção positiva dos adolescentes quanto ao ato de doar órgãos, originadas principalmente de fatores religiosos e de motivação altruísta, sendo elas: 1- o ato de doar órgãos não é uma forma de comprar o perdão por pecados praticados $(87,2 \%)$; 2- o espírito não fica preso à parte do órgão doado se ele continuar a funcionar em outros corpos $(85,1 \%)$; 3- a doação de órgãos não é um ato doloroso, pois a alma não permanece ligada ao corpo físico $(73,4 \%)$; 4- a aparência do doador não se modifica com a retirada dos órgãos $(44,7 \%)$; 5- deve-se doar porque, depois de morto, para mais nada os órgãos servirão $(41,5 \%)$; 6- ser doador implica responsabilidade (39,4\%); 7- a única saída para salvar uma vida não é o transplante $(34,0 \%) ; 8$ não têm medo de doar seus órgãos $(28,7 \%)$.

Foram evidenciadas, também, cinco crenças negativas menos favoráveis à doação de órgãos, sendo elas: 1- não autorizariam a doação dos órgãos de um familiar, por não terem discutido o tema com ele em vida $(66,0 \%)$; 2- acreditam no tráfico de órgãos entre as equipes médicas (55,3\%); 3 não são doadores, por medo de um falso diagnóstico de morte encefálica (33,0\%); 4- acreditam que, uma vez internado no hospital, existe a possibilidade de roubarem seus órgãos $(28,7 \%)$; 5- não percebem nobreza em ser doador ou que isso seja algo que propicie uma sensação de paz e bemestar $(27,7 \%)$

Estes dados também evidenciam as crenças populares em que os maiores medos não são referentes às questões filosóficas ou espirituais, mas se fundamentam na questão do preconceito, ou seja, no desenvolvimento de uma opinião negativa a respeito de um conceito, ou fato, originado pelo desconhecimento e ignorância. No caso dos transplantes, as pessoas desconhecem os procedimentos que envolvem todo o processo e acreditam em possibilidades fantasiosas $^{(26,28)}$.

Estudos mostram que apenas a educação não é suficiente para solucionar tais problemas, sendo necessário o estabelecimento de técnicas cognitivas e comportamentais capazes de amenizar o temor dos doadores. A educação deve estar baseada em programas formulados e desenvolvidos por profissionais de saúde e realizada com a participação de profissionais de publicidade, da educação e que trabalham com tecnologia da informação ${ }^{(26,28)}$.

Percebe-se que ainda não se formou uma opinião pública positiva sobre o fato de ser doador de órgãos de tal forma que a sociedade espere tal comportamento das pessoas, como ocorre no caso do fumo ou das drogas ${ }^{(28)}$.

Quando os adolescentes foram questionados se deveriam ou não ser doadores de órgãos, segundo a opinião de pessoas significativas para eles, 53,2\% (50/94) responderam que não deveriam. Estes dados caracterizam uma norma social com grande peso negativo sobre a formação da opinião dos adolescentes, e permite concluir que o grau de motivação destes jovens para se tornarem doadores de órgãos é muito baixo, pois segundo seus referentes sociais, não devem ou não sabem se devem aderir a tal comportamento.

Para verificar possíveis relações de influência entre o grau de conhecimento dos participantes sobre o transplante e doação de órgãos e as crenças desses adolescentes foi realizado o Teste de Mann-Whitney associando-se o conhecimento com a soma das crenças, como apresentado ao Quadro 1. 
Quadro 1 - Resultados do teste de Mann-Whitney para comparação do escore obtido entre as crenças, soma das crenças e os escores de conhecimento dos alunos - São Paulo - 2002

\begin{tabular}{|ccccccccc|}
\hline Escore & Variável & $\mathbf{n}$ & Média & $\begin{array}{c}\text { Desvio } \\
\text { Padrão }\end{array}$ & Mediana & Mínimo & Máximo & p-valor \\
\hline$<4$ & SOMAC & 61 & 54,8 & 8,27 & 55,0 & 36,0 & 69,0 & \\
$>4$ & SOMAC & 33 & 57,2 & 6,63 & 58,0 & 44,0 & 75,0 & 0,17 \\
\hline
\end{tabular}

Os resultados apontaram que, no grupo todo, há uma tendência muito próxima ao valor máximo, revelando crenças fortemente positivas ou negativas, ou seja, tanto os indivíduos com maior conhecimento (escore $\geq 04$ ), quanto aqueles com menor conhecimento (escore < 04), possuem as mesmas crenças, positivas ou negativas, em relação ao comportamento esperado ( $\mathrm{p}$-valor=0,17).

Para verificar a consistência interna do instrumento elaborado para esta fase da pesquisa foi aplicado o coeficiente $\alpha$ de Cronbach. Os valores obtidos na análise destas crenças oscilaram entre $\alpha=0,48$ e $\alpha=0,59$ ao serem incluídos todos os itens correspondentes à avaliação das crenças apresentadas aos participantes.

O teste revelou que, para se desenvolver a segunda etapa da TRA, a ser aplicada em projeto futuro, três questões específicas deverão ser retiradas do instrumento definitivo ou modificadas, pois não tiveram poder discriminatório. Ao se refazer o teste com as questões excluídas o coeficiente elevou-se para $\alpha=0,62$, índice considerado satisfatório, de acordo com a literatura ${ }^{(29)}$, revelando que, para esta fase do estudo, o instrumento utilizado permitiu atingir os objetivos estabelecidos.

\section{CONCLUSÃO}

Os resultados obtidos neste trabalho permitem concluir, que no grupo estudado:

- o conhecimento é deficiente e limitado em relação aos conceitos de morte encefálica, transplante e doação de órgãos;

- foram evidenciadas oito crenças positivas relativas ao comportamento de ser doador de órgãos;

- foram evidenciadas cinco crenças negativas, ou menos favoráveis à doação de órgãos.

O estudo permitiu, também, verificar a consistência interna do instrumento aplicado para a colheita de dados $(\alpha=0,62)$ e possibilitar sua adequação.

Estes resultados, embora incipientes, permitiram verificar que a lacuna e o descompasso existentes entre o número de doadores e a demanda por transplantes de órgãos constituem-se problemas relacionados à captação e distribuição de órgãos que não podem permanecer confinados a discussões acadêmicas.
Em que pese o fato de o estudo ter sido desenvolvido com pequeno grupo de adolescentes, acreditamos que os resultados aqui obtidos refletem uma mesma realidade: há muita desinformação entre a população, permitindo que crenças desfavoráveis à doação de órgãos tornem-se cada vez mais arraigadas.

As informações veiculadas pelos meios de comunicação de massa, não têm sido suficientes, nem eficientes, para modificar este panorama; ao contrário, reforçam o imaginário popular, repleto de mitos, crendices e desinformações sobre a atividade relacionada aos transplantes no Brasil e no mundo.

Face a esta realidade, o enfermeiro deve tomar posição e atuar, como educador, para modificar a opinião pública quanto aos conceitos errôneos, mas as crenças desfavoráveis só poderão ser modificadas se os educadores estimularem a população a participar de debates sobre transplantes de órgãos e sobre legislação.

Modificar a realidade existente implica, também, desenvolver programas planejados, implementados e avaliados dentro de um processo educativo contínuo, respaldado por referenciais teóricos e modelos cientificamente reconhecidos, destinados a todos os segmentos da comunidade.

Não há dúvidas, que pela complexidade do tema, tomar a decisão de ser um doador de órgãos é um processo que envolve aspectos cognitivos, como conhecimento correto a respeito do assunto. Os aspectos afetivos, porém, como crenças pessoais e crenças normativas, que levarão cada indivíduo a fazer sua opção, também devem ser considerados quando se pretende mudanças de atitudes mais profundas. Sob esta ótica, a Teoria da Ação Racional mostrou-se um instrumento adequado, que pode ser utilizado por enfermeiros no planejamento de programas educativos, pois busca entender a construção do comportamento humano tanto sob o aspecto cognitivo como afetivo.

Reconhecemos, que por se tratar de matéria que envolve aspectos complexos na formação da intenção e do comportamento das pessoas, novos e contínuos estudos devem ser desenvolvidos para um conhecimento mais aprofundado sobre esses aspectos. Além disso, é necessário capacitar profissionais ligados à educação formal, em escolas de ensino fundamental, médio e superior, bem como os ligados à educação em saúde, para promover esclarecimentos e debates sobre transplantes e doação de órgãos, proporcionando às pessoas condições para uma tomada de decisão consciente. 


\section{REFERÊNCIAS}

(1) World Health Organization (WHO). Human organ transplantation. Geneva; 1991.

(2) Neumann J. Transplante de órgãos e tecidos. São Paulo: Sarvier; 1997.

(3) Van Buren CT, Barakat O. Organ donation and retrieval. Surg Clin North Am. 1994;74(5):1055-81.

(4) Conselho Federal de Medicina. Resolução n. 1346, de 8 de agosto de 1991. Dispõe sobre os princípios norteadores para diagnóstico de morte encefálica. Diário Oficial da União, Brasília, 17 out. 1991. p. 22731.

(5) Brasil. Decreto n. 879, de 22 de julho de 1993. Regulamenta a Lei n. 8.849, de 18 de novembro de 1992, que dispõe sobre a retirada e o transplante de tecidos, órgãos e partes do corpo humano, com fins terapêuticos, científicos e humanitários. Diário Oficial da União, Brasília, 23 jul. 1993. Seção 1, p. 10298.

(6) Fiorelli AI. Critérios de seleção e manutenção de doadores. Rev Fac Med USP 1992/1993; (n. esp).

(7) Lamb D. Transplantes de órgãos e ética. São Paulo: Hucitec; 2000.

(8) Meneghin P. O enfermeiro construindo e avaliando ações educativas na prevenção da AIDS [tese]. São Paulo : Escola de Enfermagem da USP; 1993.

(9) Ajzen I, Fishbein M. Understanding attitudes and predicting social behavior. Englewood Cliffs: Prentice Hall; 1980.

(10) Gallani MCBJ. O exercício físico e o paciente infartado: determinantes comportamentais [tese]. São Paulo: Escola de Enfermagem da USP; 2000.

(11) Nunnaly J, Berstein W. Psychometric theory. $3^{\text {rd }}$ ed. New York: McGraw-Hill; 1994.

(12) Fishbein M, Jacard JJ. Theoretical and methodological considerations in the prediction of family planning intentions and behavior. Rep Res Soc Psychol. 1973;4:37-51.

(13) Instituto Brasileiro de Geografia e Estatística (IBGE). Resumo por assunto: religião [online]. 15 fev. 2001. Disponível em $<$ http://www.sidra.ibge.gov.br> [Acesso em 15 dez. 2004].

(14) Gonçalves RS. Entre o pensar e o agir: a vulnerabilidade dos adolescentes à gravidez, às DST e à AIDS. In: $4^{\circ}$ Encontro Nacional de Educadores na Prevenção da AIDS; 2000 jun; São Paulo. São Paulo: EducAIDS; 2000.

(15) Val LF. Estudo dos fatores relacionados à aids entre estudantes do ensino médio [dissertação]. São Paulo: Escola de Enfermagem da USP; 2000.
(16) Duarte OS, Pericoco S, Miyazaki MCOS, Ramalho HJ, AbbudFilho M. Atitudes do público brasileiro em relação à doação e transplante de órgãos. JBT. 2000;3(1):1-11.

(17) Meneghin P. Entre o medo da contaminação pelo HIV e as representações simbólicas da AIDS: o espectro do desespero contemporâneo. Rev Esc Enferm USP. 1996;30(3):399-415.

(18) Meneghin P, Stefanelli MC. Aids, mass media and health education. In: Proceedings of the $1^{\text {st }}$ International Conference On Community Health Nursing Research; 1993 sept. 26-29; Alberta (CA). Alberta (CA), Edmonton Board of Health; 1993. p. 134.

(19) Parker R. A construção da solidariedade: AIDS, sexualidade e política no Brasil. Rio de Janeiro: Relume-Dumará; 1994.

(20) Campos HH. Aumento do número de transplantes e da doação de órgãos e tecidos: processo de construção coletiva [online]. Disponível em <htpp://www.abto.com.br/boletim> [Acesso em 15 jul. 2001].

(21) Oliveira CIC. Os motivos que levam à recusa familiar quanto à doação de órgãos. JBT. 2001; 4(supl):111.

(22) Registro Brasileiro de Transplantes. São Paulo: Associação Brasileira de Transplante de Órgãos (ABTO). 2000;6(4).

(23) Zinn GR, Gonçalves RC, Felix SN, Nogueira SC, Massarollo MCKB. Doação e transplante de órgãos: concepção dos alunos do curso de graduação em enfermagem de uma instituição pública de ensino de São Paulo. JBT. 2001;4(supl):177.

(24) Amaral ASR. Conhecimento da doação de órgãos entre médicos professores. JBT. 2001;4(supl):27.

(25) Abbud-Filho M, Miyazaki MCOS, Ramalho HJ, Domingos N, Garcia R, Pucci F. Survey of concepts and attitudes among healthcare professionals toward organ donation and transplantation. Transplant Proc. 1997;29: 3242-3.

(26) Verble M, Worth J. Dealing with the fear of mutilation in the donation discussion. J Transpl Coord. 1999; 9(1):54-6.

(27) Guadagnoli E. The public's willingness to discuss their preference for organ donation with family members. Clin Transplant. 1999;13(4):342-8.

(28) Doxsey JR, Vasconcellos LM, Gusmán RC, Belling RA. Opinião pública frente à doação de órgãos: perfil após 10 anos. JBT. 2001;4(supl):27.

(29) Dela Coleta MF. O modelo de crenças em saúde: uma aplicação a comportamentos de prevenção e controle da doença cardiovascular [tese]. Brasília: Instituto de Psicologia da UnB; 1995. 